\title{
Contribuições históricas do Movimento Hip Hop para a luta contra o racismo e para a comunicação da juventude negra e periférica ${ }^{1}$
}

\section{Historical Contributions of the Hip Hop Movement to the Fight against Racism and to the Communication of Black and Peripheral Youth}

Pablo Nabarrete Bastos ${ }^{2}$

Resumo: Este artigo analisa as imbricações históricas dos Movimentos Negros e do Movimento Hip Hop a partir de narrativas e histórias de vida de intelectuais orgânicos da primeira e segunda geração do Hip Hop. São combinadas análises históricas e pesquisa de campo de caráter qualitativo, com inspiração etnográfica. Nosso foco principal são as relações históricas entre os Movimentos Negros, o Movimento Hip Hop e as contribuições do Hip Hop para a luta contra o racismo, a construção de identidade étnico-racial e a comunicação da juventude negra e periférica.

Palavras-chave: Movimentos Negros; Movimento Hip Hop; Identidade étnico-racial; Comunicação.

\begin{abstract}
This paper analyzes the historical imbrications of Black Movements and the Hip Hop Movement from the narratives and life history of organic intellectuals of the first and second generation of Hip Hop. Historical analyzes and qualitative field research with ethnographic inspiration are combined. Our main focus is on historical relationships between Black Movements, Hip Hop Movement and Hip Hop's contributions to the fight against racism, the construction of ethnic-racial identity, and the communication of black and peripheral youth.
\end{abstract}

Keywords: Black Movements; Hip Hop Movement; Ethnic-racial Identity; Communication.

\footnotetext{
${ }^{1}$ Neste artigo, revisitamos, com centralidade na questão étnico-racial, a pesquisa realizada com o Movimento Hip Hop do ABC Paulista para nossa Dissertação de Mestrado, concluída na Escola de Comunicações e Artes da Universidade de São Paulo, em 2008. Conquanto tenhamos iniciado o Mestrado em 2005, a pesquisa teve início em 2003.

${ }^{2}$ Professor do Departamento de Comunicação Social do Instituto de Artes e Comunicação Social da Universidade Federal Fluminense (IACS-UFF). Professor permanente do Programa de Pós-Graduação em Mídia e Cotidiano (PPGMC-UFF). Doutor em Ciências da Comunicação, linha de pesquisa de Comunicação, Cultura e Cidadania, pela Escola de Comunicações e Artes da Universidade de São Paulo (ECA-USP). Possui pós-doutorado em Estudos Culturais pelo Programa Avançado de Cultura Contemporânea da Universidade Federal do Rio de Janeiro (PACC-UFRJ). Líder do Laboratório de Pesquisa em Comunicação Comunitária e Publicidade Social (LACCOPS). Coordenador do GP Comunicação para a Cidadania da Intercom. Pesquisa hegemonia, contrahegemonia, hegemonia popular, engajamento, movimentos sociais e comunicação popular. Possui experiência profissional nas áreas de Planejamento de Campanha e Redação Publicitária, com atuação em agência de comunicação e no terceiro setor.
} 


\section{Introdução}

Este é um momento histórico oportuno para revisitarmos pesquisa com o Movimento Hip Hop do ABC Paulista, realizada entre 2003 e 2008, trazendo para este artigo um recorte ainda não publicado: a centralidade da matriz étnico-racial e da histórica luta antirracista na constituição da vertente brasileira do Movimento Hip Hop. Este artigo está sendo finalizado no décimo dia de intensas manifestações antirracistas nos Estados Unidos, que tiveram início após o covarde assassinato do homem negro George Floyd por, agora, ex-policiais norte-americanos. Umas de suas últimas palavras, I can't breathe, em português "Não consigo respirar", foi entoada em manifestações que se espalharam pelo país. A expressão já era utilizada pelo movimento Black Lives Matter, em português "Vidas negras importam", nos Estados Unidos, após a morte de Eric Garner, em julho de 2014, estrangulado por um agente do Departamento de Polícia de Nova York. No Brasil, no dia 18 de maio de 2020, o garoto de 14 anos João Pedro Mattos foi assassinado no Complexo do Salgueiro, em São Gonçalo, no Rio de Janeiro, em operação da Polícia Civil e da Polícia Federal. O Movimento Hip Hop, que surge em 12 de novembro de 1974 nos Estados Unidos, na esteira do fortalecimento do movimento negro, feminista e de juventude, vem atuando no Brasil desde meados da década de 1980 e segue denunciando e lutando contra o racismo estrutural e o genocídio da juventude negra. Dessa maneira, cremos que retomar neste momento o debate sobre o Hip Hop e destacar sua cor preta seja um ato científico e político relevante. Importante também destacar como as questões de classe e raça são imbricadas na história e no cotidiano de exploração, expropriação e opressão das classes populares. Ao pesquisar as relações de raça e classe no Brasil, Ianni (2004) demonstra como as desigualdades de raça são estruturadas por desigualdades sociais e por estruturas de domínio desenvolvidas e perpetuadas pela classe branca dominante e seus aparatos ideológicos. A tese central é a seguinte:

A história do povo revela que há diversidades raciais que são criadas e recriadas no interior das desigualdades sociais. Aliás, as características raciais são produzidas socialmente nas relações entre diferentes etnias. Nesse sentido é que raça, o preconceito racial e o racismo são produtos das relações entre membros de grupos que se consideram e agem como diferentes, desiguais (IANNI, 2004, p. 7).

O termo "Hip Hop" significa, numa tradução da língua inglesa, saltar e girar o quadril, uma referência à dança de rua, que é um dos elementos artísticos do Movimento Hip Hop. Era 
o nome de uma festa que acontecia, no início dos anos 1970, no n ${ }^{\circ} 123$ da Fourth Street, em Nova York, nos EUA. Quem supostamente criou a expressão foi o MC Lovebug Starski ${ }^{3}$, nas festas de rua, ou block parties, promovidas por Afrika Bambaataa. Mas foi Afrika Bambaataa quem difundiu e popularizou o termo para o mundo. Em 12 de novembro de 1973, Bambaataa ${ }^{4}$ criou a Universal Zulu Nation e, um ano depois, o Movimento Hip Hop. Afrika Bambaataa percebeu nas diferentes expressões culturais e artísticas que emergiam entre os afro-americanos, afro-caribenhos e latinos da periferia do Bronx-Nova York uma forma de conter/manifestar os conflitos entre as gangues, através da formação cultural e do fortalecimento de suas identidades. Eram os seguintes elementos artísticos: o DJ (Disc Jockey), quem "pilota" os toca-discos e anima a festa; o MC (Master of Ceremony, ou mestre de cerimônias), quem canta e comanda a festa; e esses dois elementos constituem o rap (sigla de rhythm and poetry, ritmo e poesia); a dança de rua, sendo o breaking a mais praticada e conhecida; e, por fim, o graffiti ${ }^{5}$, a arte plástica que era utilizada inicialmente para marcar o território das gangues. No início dos anos 1980, devido ao crescimento do Hip Hop e às distorcidas apropriações dos elementos artísticos pela indústria cultural norte-americana, que transformou o Hip Hop em sinônimo de rap, Afrika Bambaataa propõe o quinto elemento, o conhecimento, com o objetivo de fortalecer a história e o sentido do Hip Hop construído pelos seus criadores. Dez anos depois da criação do Hip Hop nos EUA, também no bojo de transformações históricas globais e nacionais - como a intensificação do processo de globalização, com os avanços das tecnologias da informação e dos meios de comunicação, e o processo de redemocratização do Brasil -, o Hip Hop chega a nosso país, através da dança de rua, primeiramente em São Paulo e no ABC Paulista.

Há uma grande diversidade no posicionamento político, nas formas de trabalhar as matrizes sociais, étnico-raciais, de gênero e geração, de acordo com as referências históricas e culturais de cada território e dos integrantes das organizações de Hip Hop: as posses. Posse ${ }^{6}$ é

\footnotetext{
${ }^{3}$ Disponível em: http://www.zulunation.com. Acesso em: 21 abr. 2020.

${ }^{4}$ Embora carregada de personalização, essa é a narrativa hegemônica no Movimento Hip Hop, que ouvimos de diversos militantes entrevistados. Também está nos canais de informação da Universal Zulu Nation. A narrativa também está presente em ROCHA; DOMENICH; CASSEANO, 2001.

${ }^{5}$ A predileção de escrever em italiano, graffiti, é defendida por muitos artistas. Por isso também adoto esta forma de grafia. "A palavra aqui usada e a grafia adotada - graffito - vêm do italiano, inscrição ou desenhos de épocas antigas, toscamente riscados a ponta ou carvão, em rochas, paredes etc. Graffiti é o plural de graffito. No singular, é usada para significar a técnica (pedaço de pintura no muro em claro e escuro). No plural, refere-se aos desenhos (os graffiti do Palácio de Pisa). A despeito de outras grafias adotadas, mesmo aquela dicionarizada pelo Aurélio, escolhi a de origem italiana, porque há palavras, no meu entender, que devem permanecer em sua grafia original pela intensidade significativa com a qual se textualizam dentro de um contexto" (GITHAY, 1999, p. 13).

${ }^{6} \mathrm{O}$ nome posse não é mais frequentemente utilizado pela militância do Hip Hop, como era durante a década de 1990, sendo preferido o nome organização. Verificamos essa mudança em meados dos anos 2000, com o
} 
o nome criado pelos integrantes do Hip Hop para as organizações em que trabalham os elementos artísticos - MC, DJ, breaking e graffiti - em torno de uma visão de mundo e um projeto político, os quais eles entendem e denominam como o quinto elemento. As posses atuantes no ABC Paulista são: Posse Hausa, de São Bernardo do Campo, que trabalha com centralidade na questão racial; e as organizações nacionais Nação Hip Hop Brasil, que atua em Santo André, Ribeirão Pires, Mauá e Rio Grande da Serra, com centralidade na questão social, na luta de classes, e a Zulu Nation Brasil, de Diadema, com foco na questão cultural/cidadã.

Este artigo retoma dados substanciais e inéditos ${ }^{7}$ de pesquisa realizada com o Movimento Hip Hop do ABC Paulista, entre 2003 e 2008, com o intuito de compreender os sentidos do Hip Hop para os intelectuais orgânicos do Movimento. Conquanto a pesquisa de campo tenha sido realizada há mais de 10 anos (BASTOS, 2008a), mostrar as imbricações históricas dos Movimentos Negros e do Movimento Hip Hop permanece relevante, sobretudo pelo distanciamento da temática racial ocorrido durante a década de 1990, principalmente na produção artística do Movimento ${ }^{8}$. São combinadas análises históricas e pesquisa de campo de caráter qualitativo, com inspiração etnográfica. Neste artigo, nosso foco principal são as relações históricas entre os Movimentos Negros, o Movimento Hip Hop e as contribuições do Hip Hop para a luta contra o racismo, a construção de identidade étnico-racial e a comunicação da juventude negra e periférica.

\section{Hip Hop: movimento social negro e juvenil}

No primeiro estudo brasileiro sobre o Hip Hop, a Dissertação de Mestrado Movimento negro juvenil: um estudo de caso sobre jovens rappers de São Bernardo do Campo, elaborada na Faculdade de Educação da Universidade de São Paulo (FE/USP), em 1996, a autora Elaine Nunes de Andrade utiliza mais de trezentas páginas para caracterizar e demonstrar o Hip Hop como movimento negro juvenil, sendo o foco empírico o surgimento e trabalho da Posse Hausa, de São Bernardo do Campo, que também analisamos neste artigo. Em Hip Hop: Cultura e política no contexto paulistano, tese publicada em 2006, no doutorado de Antropologia Social também da USP (PPGAS), João Batista de Jesus Felix analisa o Hip Hop como parte e

\footnotetext{
surgimento de organizações nacionais de Hip Hop. Contudo, é importante destacarmos que a principal organização que constitui o corpus deste artigo ainda se autodenomina como Posse Hausa.

${ }^{7}$ Publicamos dois artigos (BASTOS, 2008b; 2014) que são referência para a discussão que realizamos aqui.

${ }^{8}$ Essa é a visão da militância do Hip Hop que atua com centralidade na questão racial.
} 
continuidade da luta do Movimento Negro Brasileiro. O autor avalia que o debate sobre a relação entre cultura e política, que ele analisa no trabalho das pioneiras posses brasileiras e paulistanas Núcleo Cultural Força Ativa, Aliança Negra e Conceitos de Rua, é uma discussão histórica no Movimento Negro Brasileiro. É inegável a matriz afro-brasileira do Movimento Hip Hop e sua relação com a diáspora africana e suas repercussões históricas, políticas, ideológicas e culturais.

O Hip Hop surge como uma manifestação cultural da juventude negra da periferia, primeiramente com a dança breaking. Paulatinamente, a consciência de movimento social da juventude negra vai amadurecendo, as lideranças se formam, os objetivos são definidos e uma organização é constituída. O fato de ser um movimento formado e dirigido para resolver os problemas, as carências e as mediações simbólicas da juventude faz com que o Hip Hop tenha especificidades que o diferencia de outros movimentos sociais. Ele também se distingue de outros movimentos de juventude por conciliar o caráter social e político com o cultural e simbólico de maneira imbricada, com destaque para a dimensão política das produções artísticas.

A Posse Hausa possui como lema "Hip Hop com responsabilidade racial”. Importantes lideranças da Posse são também militantes do Movimento Negro Unificado (MNU). João Batista de Jesus Felix (2006) apresenta o Hip Hop como continuação da linha evolutiva do Movimento Negro no Brasil. Ainda em sua pesquisa de Mestrado, Chic Show e Zimbabwe e a construção da identidade nos bailes black paulistanos (2000), 80\% dos entrevistados apontaram que conheciam o Movimento Negro e, ao serem indagados para citar nomes de entidades negras, quase todos mencionaram os grupos ligados ao Hip Hop. Desse modo Felix concluiu que:

[...] as informações que [o público dos bailes pesquisados] obtém sobre as lutas contras as discriminações existentes contra o negro [...] vêm com a atuação dos rappers. Assim, ao confundir e descrever o rap como Movimento Negro (MN), estas pessoas não estão demonstrando falta de informação sobre o que seria esta forma de organização social, mas sim nos revelando uma nova expressão dela (FELIX, 2006, p. 20).

A pesquisa pioneira de Andrade (1996) foi iniciada em 1993 e, nesse período, as posses estavam surgindo, e seus conceitos de organização social e política eram ainda incipientes. No 
entanto, Honerê ${ }^{9}$, da Posse Hausa, fundada em 1993, aponta em entrevista que, na década de 1990, o Hip Hop tinha um recorte racial mais nítido e definido, havendo um branqueamento sobretudo dos temas do rap no final da década, o que ele considera extremamente prejudicial para a juventude negra. O Hip Hop pode ser compreendido como movimento social negro devido a suas matrizes africanas, suas temáticas e lutas raciais, seu papel como referencial identitário e na elevação da autoestima de jovens negros e negras da periferia. Contudo, o Hip Hop possui suas especificidades como organização política, cultural e artística, na formação de lideranças e nas formas de lidar com as matrizes sociais, culturais, raciais, com as histórias regionais. Honerê, que quando entrevistamos era coordenador nacional de comunicação do MNU e coordenador geral da Posse Hausa, avalia que ambas as frentes de luta são importantes e que há uma simbiose entre elas, mas sempre se refere ao Movimento Negro e ao Hip Hop como distintos.

A Nação Hip Hop Brasil tem parceria com a UNEGRO - União dos Negros pela Igualdade Racial -; à época da pesquisa, a Zulu Nation Brasil tinha como uma de suas principais lideranças o MC Levy, militante histórico do Movimento Negro, que havia sido do MNU. Desde o início do Hip Hop, há entre os movimentos organicidade, parcerias e fluxo de lideranças, convergências, mas também divergências. Um dos principais conflitos dava-se em torno da seguinte questão: os militantes e artistas do Hip Hop consideravam os militantes do Movimento Negro como a elite negra, no aspecto econômico, político e intelectual, e o Hip Hop era da favela, da "quebrada", do jovem negro da periferia, lugar em que as ações e ideias do MN não chegavam, segundo a militância do Hip Hop.

O primeiro contato entre o MN e o Hip Hop ocorreu em 1989. Foi um incidente trágico que aproximou os jovens que estavam no Hip Hop dos mais antigos militantes negros. Um jovem negro chamado Marcelo saiu de um baile do Clube da Cidade, que ficava na rua Mário de Andrade, na Barra Funda, e pegou o metrô sentido Zona Leste. Ele estava cantando um rap, e um policial quis impedir que batucasse e cantasse no metrô. Quando estavam na estação Tatuapé, o policial disparou um tiro na cabeça do rapaz, que morreu.

Naquele ano, já havia um início de organização no Movimento Hip Hop, principalmente em torno da dança de rua, com reuniões na estação São Bento do metrô, e do rap, cujos adeptos frequentavam a praça Roosevelt e criaram o Sindicato Negro, considerado o princípio do que seriam as posses. Após o fato relatado, jovens rappers procuraram o MNU para fazer um

\footnotetext{
${ }^{9}$ Entrevista concedida por Honerê ao autor em 26 de novembro de 2007.
} 
protesto contra a morte de Marcelo. MC Levy ${ }^{10}$, que era do MNU e do Sindicato dos Marceneiros, conseguiu junto ao sindicato o patrocínio para uma passeata com um caminhão e panfletos desde o largo São Francisco, onde haveria apresentação de grupos de rap, até a praça da Sé. Como Levy era locutor de eventos e agitador cultural, foi o locutor dessa manifestação. Eles foram seguidos pela polícia enquanto protestavam fazendo duras críticas à violência policial.

Em seguida, no início dos anos 1990, o MNU realizou um seminário sobre juventude e questão racial, na Câmara Municipal de São Paulo, e convidou alguns rappers para comporem a mesa. Estavam presentes no debate: Mano Brown, no começo do grupo Racionais MCs, e Xis, na época MC do grupo DMN. Até então não havia no MNU discussões específicas sobre a juventude negra. Alguns de seus integrantes e dirigentes eram jovens que vivenciavam as vicissitudes da questão geracional, porém não as discutiam politicamente.

O Movimento Hip Hop provoca uma oxigenação nesse sentido, movimentando e colocando a juventude pobre e negra na agenda política. Mas a inserção dos jovens ligados ao movimento nos debates não foi tão rápida em outros Movimentos Negros quanto foi no MNU; ocorreram alguns embates. Na organização UNEGRO - União de Negros pela Igualdade -, segundo Levy, a liderança acreditava que o Hip Hop poderia atrapalhar o Movimento Negro mais organizado. Uma das grandes polêmicas era configurada quando o Movimento Negro defendia as denominações "negros" e "negras", enquanto o Movimento Hip Hop defendia as denominações "pretos" e "pretas", segundo Levy, devido à influência do Hip Hop norteamericano. Ele ainda explica que o Movimento Negro opta por enfatizar o termo negro para se contrapor diametralmente às características negativas atribuídas historicamente à palavra, para colidir e afirmar a identidade étnico-racial negra. Mas Levy acredita que todos fazem parte de uma mesma luta pela negritude, não importa se como pretos e pretas ou negros e negras. Com o passar do tempo, quase a totalidade das organizações ligadas ao Movimento Negro passou a ter alguma ligação com o Movimento Hip Hop; e a UNEGRO é hoje parceira da organização nacional Nação Hip Hop Brasil. A publicação Cadernos Negros, da organização Quilombhoje, nascida com o fortalecimento do Movimento Negro no final dos anos 1970, tem como autores importantes, principalmente de poesias, os artistas do Movimento Hip Hop.

Nas ciências humanas o conceito de raça já perdia seu status científico nos "estertores" da Segunda Guerra Mundial (FELIX, 2006, p. 40). Entretanto, o termo é ainda cercado de

\footnotetext{
${ }^{10}$ Entrevista concedida por Mc Levy ao autor em 22 de outubro de 2007.
} 
discussões e conflitos, certamente pelo fato de a questão racial mediar as relações sociais, culturais e políticas, sejam históricas ou cotidianas, por se constituir como referencial identitário central para os negros e negras que se assumem politicamente como tal, por mediar a história na visão desses agentes sociais e suas organizações, e por colidir com o grande mito da democracia racial brasileira; a raça existe concreta e historicamente nesses termos. Como afirma Stuart Hall:

A diferença genética - o último refúgio das ideologias racistas - não pode ser usada para distinguir um povo do outro. A raça é uma categoria discursiva e não uma categoria biológica. Isto é, ela é a categoria organizadora daquelas formas de falar, daqueles sistemas de representação e práticas sociais (discursos) que utilizam um conjunto frouxo, frequentemente pouco específico, de diferenças em termos de categorias físicas e corporais, etc. como marcas simbólicas, a fim de diferenciar socialmente um grupo do outro (HALL, 1999, p. 63).

\section{Breve histórico do movimento negro brasileiro}

Ainda na década de 1920 surge o jornal O Clarim d'Alvorada, que Felix (2006) aponta como o mais importante jornal da Imprensa Negra na década de 1930. Octávio Ianni (2004, p. 116) destaca a atuação política do jornal: “Em março de 1929, em São Paulo, o jornal O Clarim d'Alvorada propõe a realização do $1^{\circ}$ Congresso da Mocidade Negra do Brasil. Propunha uma discussão 'em torno da nossa angustiosa situação de negros brasileiros'.” Em 16 de setembro de 1931, em São Paulo, funda-se a Frente Negra Brasileira (FNB), primeira organização social e política do negro brasileiro pós-Abolição. Segundo Felix (2006), a FNB era movida pela ideologia nacionalista e seu principal objetivo político era a inclusão do negro na sociedade brasileira, o que equivalia a assumir os padrões de comportamento da "sociedade branca". Essa postura política da FNB era coerente com os princípios político-ideológicos do negro brasileiro daquele período histórico, que vivenciava os percalços da integração na sociedade de classes. Ianni avalia que o aspecto preponderante da ideologia do negro e do mulato era o “branqueamento", principalmente social, mas também biológico:

A nosso ver, o ideal de branqueamento, manifesto por todo grupo, não é apenas produto do preconceito estético, mas, principalmente, das condições efetivas de contato. Assim, o ideal de branquidade não diz respeito apenas aos caracteres somáticos do indivíduo, mas, em primeiro lugar, às condições 
sociais a que negros e mulatos aspiram. $O$ que o negro deseja é o "branqueamento social". Assim, às atitudes desfavoráveis do branco, o negro e o mulato se ajustam por meio do símbolo comum aos dois grupos: a cor. Essa é uma das consequências subjetivas do preconceito de cor, visto em termos da reação das personalidades afetadas, direta ou indiretamente, por suas manifestações (IANNI , 2004, p. 97).

Portanto, nesses primórdios do movimento negro brasileiro, elementos culturais e simbólicos que remetem à ancestralidade africana, a uma identidade afrocentrada, como o samba, a capoeira e o candomblé, não eram vistos com bons olhos pelos militantes, pois eram empecilho para a inserção na "sociedade branca brasileira". Outro fator apontado por Felix (2006) como causador dessa postura da entidade era a influência dos paradigmas da mestiçagem, bastante em voga no período, que defendiam a ideia da democracia racial, de um único povo mestiço. Portanto, seria uma incoerência ser brasileiro e assumir-se como negro. Também as atividades de lazer, como o baile, posteriormente consideradas como lócus estratégico para construção e fortalecimento da identidade negra, com um viés político corolário da assunção dessa identidade étnico-racial, eram vistas com receio pelos dirigentes. Felix descreve que:

o baile, para a FNB, era visto como um mero apêndice e não como um
instrumento na construção de uma identidade negra, ou mesmo que podia
ajudar na luta pela melhoria da vida da população negra. Ele, além de divertir,
também, trazia o risco, na opinião dos dirigentes negros, de levar o
frequentador à acomodação. Assim, para a direção da Frente Negra Brasileira,
o lazer não tinha importância na luta contra discriminação, o preconceito e
o racismo. Por outro lado, como a entidade pretendia a inclusão social, a
questão da identidade não constituía um tema da agenda política (FELIX,
2006, p. 32)

Com o início da ditadura do Estado Novo, em 1937, todos os partidos políticos foram extintos e também a Frente Negra Brasileira, que havia se tornado um partido político em 1936. Contudo, esses ideais de inserção na sociedade brasileira obedecendo aos padrões brancos de comportamento mantiveram-se por décadas. MC Levy conviveu e erigiu sua subjetividade nesse confronto entre nascer negro e ser negro, entre sua condição física e as pressões dos valores culturais que não coadunavam com a história da sua família e do seu povo. Ele nasceu em 3 de novembro de 1952. Sua avó Sabá foi filha de ventre livre, e seu avô Levy Constâncio era filho de um marinheiro francês e nascera em um navio vindo para o Brasil. Ao desembarcar 
no país, a família de seu avô foi para a região de Campinas. O seu pai, que era o caçula da família, receberia o nome do pai, mas foi registrado erroneamente no cartório como Constâncio Levy; então, Levy virou sobrenome de toda a família dali em diante. A sua mãe era nascida em Varginha, sul de Minas, também descendente de africanos, por parte de mãe. Ela não chegou a conhecer o pai. Levy conta que em sua casa não tinha rádio, nem televisão, e que seus pais contavam muitas histórias para ele. O pai trabalhava com coleta de lixo pela prefeitura que, naquela época, era carroça puxada a burro, e a mãe fazia serviços domésticos. A irmã mais nova virou mãe de santo do Candomblé, linha de Angola. Segundo ele, para contrariar todas as vontades de sua mãe.

\begin{abstract}
A minha mãe, como todo negro daquela época, sofreu toda imposição cultural judaico-cristã, eurocêntrica. No bairro que a gente morava, Vila Santa Maria, tinha um terreiro de Umbanda na frente da nossa casa, era o Terreiro Centro de Umbanda Pai Guaracy e o nome do pai de santo era Jair. E qual era a referência que eu tinha? Minha mãe morria de medo dali, falava que era coisa de macumba, pra não chegar perto, que era ruim. E volta e meia, vinha polícia para levar o seu Jair em cana. Então, a religião afro-brasileira era tratada como caso de polícia. Então, como é que vai ter identidade afro, identidade étnica. Minha mãe falava: "Vai pra Igreja!" (MC LEVY apud BASTOS, 2008a, p. 76).
\end{abstract}

Levy teve uma infância feliz; pobre, com privações, mas com muito futebol na rua, pipa e peão. Ele era tímido, tinha um pouco de medo, mas conta que teve que aprender a se virar na rua. A maioria dos moradores era negra e nordestina, exceto a família do seu Valdemar, o português da Vila, que era dono da mercearia, mas os filhos dele conviviam com a molecada. Ele explica que, naquela época, não existia a expressão afrodescendente, que chamavam de mulato, moreno, "de cor"; negro era muito pejorativo, tudo de ruim. Quando tinha nove anos de idade, seus pais compraram um terreno entre Vila Maria e Vila Espanhola, num local também conhecido como Casa Verde Alta. Ele lembra como percebia a questão da identidade étnica:

Nesses bairros, nesse período, entre os moradores, a questão racial, étnica, não aparece. No Brasil, a questão racial não é explícita, é muito enrustida, debaixo do pano. Mas você percebe a diferença, você percebe quando se sente incomodado. Incomodado por ser e não querer ser negro. Você quer ser o oposto, o que é legal pra sociedade. Aos nove anos eu fazia parte da Igreja Católica, porque eu procurei a Igreja, era a Igreja São Luiz de Gonzaga, a Igreja tá lá na Vila Maria até hoje. Os padres eram descendentes de franceses 
e faziam parte de um Movimento chamado Pioneiros de São Luiz, era próximo ao escotismo. E aí, eu fui ser coroinha e, o tempo todo, eu tentava falar para eles que eu também era descendente de francês, e todo mundo morria de dar risada. "Você é preto francês, rapaz?" E a chefe dos Pioneiros dizia que sim: "ele é sim, é Levy". E por que eu queria fortalecer, enaltecer esse lado francês? Porque era algo que valorizava, o que tinha valor era ser europeu cara, era ser da França. Imagina se eu ia me identificar com o terreiro do Seu Jair, em frente de casa, que a polícia prendia o tempo todo. A minha mãe dizia, inclusive, que nós (ele e suas irmãs) deveríamos misturar a raça, casar com brancos e ter filhos mais claros, pra não sofrer o que ela sofreu (ibid., p. 76-77).

Essas circunstâncias de história de vida narradas por MC Levy expressam bem os conflitos étnico-raciais que foram centrais na formação de sua subjetividade como negro durante sua infância e início da adolescência, e como os elementos culturais e simbólicos, o baile, a música, o estilo das roupas, tiveram importante papel como gancho entre ele e sua identidade. As relações sociais no ambiente em que cresceu e o contato com os brancos, a "playboyzada" do colégio Macedo Soares da Barra Funda, balizaram a compreensão e formação de sua identidade.

A construção da identidade se faz no interior de contextos sociais que determinam a posição dos agentes e por isso mesmo orientam suas representações e suas escolhas. Além disso, a construção da identidade não é uma ilusão, pois é dotada de eficácia social, produzindo efeitos sociais reais. (CUCHE, 2002, p. 182).

A própria forma de selecionar as experiências de suas lembranças denota o valor que tiveram para sua formação. "Também, para definir a identidade de um grupo, o importante não é inventariar seus traços culturais distintivos, mas localizar aqueles que são utilizados pelos membros do grupo para afirmar e manter uma distinção cultural” (ibid., p. 182).

O movimento que inaugura o novo posicionamento político de atuação dos negros e negras brasileiros, que coloca em destaque a identidade negra, o resgate de referenciais afrobrasileiros que se torna motor de luta do movimento negro e grande paradigma dos movimentos negros brasileiros é o Teatro Experimental do Negro (TEN). O projeto foi criado na década de 1940, na cidade do Rio de Janeiro, e sua maior liderança foi Abdias Nascimento. Um fato marcante foi que "a companhia teatral procurou incorporar o candomblé e o samba no enredo de suas peças, porque entendia que elas seriam manifestações populares e o 'povo', para o TEN, era visto como negro" (FELIX, 2006, p. 37). Apesar de haver no TEN, segundo Felix, o mesmo 
objetivo que havia na FNB, de melhorar a vida do negro brasileiro, há uma guinada importante para as raízes africanas.

O TEN, diferentemente da Frente Negra Brasileira, volta-se para o continente africano, em sua segunda fase, pois é lá que ele entende estarem as raízes culturais e identitárias dos negros brasileiros. Desta maneira, a cultura, naquele momento, deixa de ser simples artefato de lazer, para ser vista como instrumento legítimo na luta antirracista (FELIX, 2006, p. 38).

O TEN promoveu outras atividades, como a escolha dos títulos de "Rainha das Mulatas" e "Boneca de Piche" para, de acordo com Abdias, "reeducar o gosto estético (dos negros) pervertido pelas pressões e consagração dos padrões brancos”. Promoveu também, em 1935, um concurso de artes plásticas com o tema Cristo Negro; em 1945, a Convenção do Negro Brasileiro, preparatória do I Congresso do Negro Brasileiro, que ocorreu em 1950 e foi importante marco do movimento negro brasileiro; e a Semana do Negro, em 1955 (FELIX, 2005, p. 39).

Sobre a declaração final do I Congresso do Negro Brasileiro, Ianni aponta que:

[...] criticam a situação econômica social e cultural desvantajosa em que se acham, em comparação com o branco. Protestam contra a discriminação racial, o exclusivismo racial do branco e a ideologia da superioridade física, moral ou intelectual de uns sobre outros. Para lutar por melhores condições de vida e de competição com o branco, pedem que sejam realmente garantidos a todos as liberdades públicas asseguradas pela Constituição Brasileira de 1946 (IANNI, 2004, p. 117).

De acordo com a pesquisa de Felix, depois do TEN, a luta antirracista brasileira ficou dez anos sem uma entidade negra que se destacasse. Até que, em 1961, surge o Aristocrata Clube e, no mesmo período, o Clube 220. A primeira entidade era frequentada por uma classe média negra ascendente, e a segunda, por trabalhadores negros. Felix (2006, p. 42) assinala que “os paradigmas defendidos pelo TEN - ressignificação de uma arte e cultura negro-africana, valorização social do negro e defesa da construção de uma "identidade negra" - tornaram-se hegemônicos na luta antirracista brasileira”. Dessa maneira, podemos afirmar que as narrativas da luta antirracista encampadas pelo Movimento Hip Hop brasileiro, para além da relação com o movimento negro e o Hip Hop norte-americano, possuem raízes no TEN e nas contribuições de Abdias Nascimento. 
O autor narra, ainda, que "o Clube 220 ficou famoso por realizar, a partir de 1962, o concurso 'Bonequinha de Café"” (ibid., p. 44), numa alusão à "Bonequinha de Piche”, do TEN. O concurso coroava a negra paulistana mais bonita, e o prêmio era entregue no largo do Paiçandu, em frente à igreja da Irmandade dos Homens Pretos e um monumento à Mãe Preta. Em 1977, na entrega do prêmio, foi aberta uma faixa que protestava "Abaixo o Racismo Brasileiro". Felix relata que a atitude constrangeu as autoridades presentes - o então Presidente da República, General Ernesto Geisel, o governador do Estado, Paulo Egídio Martins, e o Prefeito da cidade de São Paulo, Olavo Egídio Setúbal -, pois "quebrava todo o clima de harmonia racial brasileira que estava sendo pretensamente comemorado" (ibid., p. 44). Após insistência do público, o diretor do Clube 220, Frederico Penteado, fez a leitura de um manifesto com duras críticas às relações raciais brasileiras. Os responsáveis pelo ato eram de um grupo de militantes negros da Liga Operária, que se definiam como trotskistas e, posteriormente, fundaram o Movimento Negro Unificado Contra Discriminação Racial (MNUCDR) depois apenas Movimento Negro Unificado (MNU).

\begin{abstract}
A intenção deles era demonstrar que as entidades culturais não serviam aos interesses da maioria da população negra e pobre (Felix, 1996 e Hanchard, 2001). Esse acontecimento marcou a luta antirracista brasileira que influenciaria bastante a existência do Hip Hop. Tanto o Aristocrata Clube como o Clube 220 atuaram politicamente seguindo os paradigmas da mestiçagem, os quais haviam influenciado as atuações da Frente Negra Brasileira e do Teatro Experimental do Negro. O rompimento com esse modelo se dará somente nos estertores da década de 1970, início da década de 80, com o lançamento do MNU (FELIX, 2005, p. 45).
\end{abstract}

\title{
4. Movimento Hip Hop do ABC Paulista: o início do Hip Hop e da Posse Hausa em São Bernardo do Campo
}

No final da década de 1980 e na maior parte da década de 1990, as discussões e as letras de rap eram, principalmente, em torno da questão racial. Ainda no início da década de 1990, quando aconteciam reuniões no Centro Recreativo Esportivo e Cultural (CREC), conhecido como "CREC Baetinha", o MNU estava se organizando e se fortalecendo também em SBC. Adomair e Ilma, membros do MNU, procuraram o Departamento de Cultura para saber o que o MNU e o Poder Público poderiam fazer conjuntamente. Eles tinham a consciência de que a questão racial estava intrinsecamente ligada com a questão cultural. Como o Movimento Hip 
Hop é formado por uma juventude majoritariamente negra, alguns passaram a caminhar junto com o MNU. O MNU passou a organizar palestras, seminários, e alguns "manos" do Hip Hop, como Blackalquimista e Nino Brown, se filiaram à organização. Honerê foi convidado por Ketu para participar dessas reuniões e também se filiou ao MNU, em 1991. O Departamento conseguiu junto à Biblioteca Manoel Bandeira do CREC uma sala de estudos sobre o negro e o índio, um projeto pioneiro no ABC Paulista. O MNU também propiciou a montagem de um tablado no CREC, onde trabalhavam a estética afro com roupas, acessórios, balangandãs e penteados, o que era muito importante para o fortalecimento da identidade e autoestima das negras e dos negros. Neuza Borges ${ }^{11}$, analista de cultura da Prefeitura de São Bernardo do Campo, nos deu o seguinte depoimento:

Adomair percebeu que o Hip Hop tinha tudo a ver com o MNU e os jovens
negros também passaram a estudar a História da África, o racismo, os porquês
do racismo. Hoje tem dados do IPEA, do IBGE que mostram em suas
pesquisas a situação do negro na escola, nas faculdades, no mercado de
trabalho, naquela época não havia dados. Então a discussão era: no Brasil
existe racismo? E eles sofriam na pele o racismo, nos problemas com a polícia,
na forma como às vezes eram tratados em locais públicos (BORGES apud
BASTOS, 2008a, p. 150-151).

Neuza Borges relatou que houve alguns questionamentos em relação às oficinas de música e poesia, porque eles só queriam ouvir e aprender o rap. O Departamento alegou que eram importantes as oficinas com todos os elementos artísticos do Hip Hop, mas que também era importante o aprimoramento dos seus conhecimentos musicais. Então, eles tinham oficinas, aos sábados no CREC, com todos os elementos artísticos do Hip Hop (MC, DJ, breaking e grafitti) e também com oficinas de música e poesia. Passaram a atuar nos bairros com Ação Cultural, envolvendo a comunidade, líderes comunitários, mulheres de clubes de mães e todas as pessoas que queriam participar. Dessas ações surgiram mostras culturais feitas nas ruas e em escolas da rede estadual. Neusa destaca que eles notaram que as pessoas reclamavam muito das pichações, então passaram a fazer oficinas de graffiti $^{12}$. As reuniões eram semanais e tudo era decidido conjuntamente, nenhuma decisão era tomada sem que os "manos" e as "minas" fossem

\footnotetext{
${ }^{11}$ Entrevista concedida por Neuza Borges ao autor no dia 15 de maio de 2007.

${ }^{12}$ Esse raciocínio faz parte do senso comum das Secretarias e Diretorias de Cultura: "Fazer oficinas de graffiti para tirar o jovem delinquente da pichação". O que é um equívoco, primeiramente porque o graffiti não tira ninguém da pichação, e em segundo lugar porque tenta utilizar arte e cultura com o intuito de "domesticar" o jovem subversivo, não com o propósito de canalizar essa energia para transformação da sociedade.
} 
consultados. Os manos sugeriram fazer um disco, uma coletânea com os grupos de rap que faziam parte daquelas atividades. Mas, além de não dominarem as técnicas, o processo era muito caro. Júlio Mendonça, também analista de cultura, propôs um livro, e todos estranharam. Argumentou que com o livro poderiam expor suas ideias, como faziam nas letras de rap, e ele apenas faria algumas correções ortográficas, sem alterar o sentido das falas. Blackalquimista ${ }^{13}$ relatou que "eles convenceram a gente". Foram feitas várias reuniões para decidir quais grupos e letras seriam incluídos no livro, o que seria abordado. Grande parte dos grupos que se apresentavam na pista de skate foi incluída na coletânea de letras de rap. Foi assim que surgiu o ABC Rap, o primeiro livro sobre o Movimento Hip Hop publicado no país, em 1992.

O evento de lançamento foi no salão do Choppapo, famosa casa noturna dos anos 1980, onde aconteciam bailes black da região, com a participação de Thaíde e DJ Hum e os Racionais MCs. No livro, há 48 letras de rap de 25 grupos: de São Bernardo do Campo, como DJ Beat e Conexão Hip Hop; de Santo André, Kalibre 12, MCs Black e Leda Hills Paradise; de Diadema, Neps e Fanáticos Gang; de São Paulo, Falcom Rap, que foi um dos fundadores do Jabaquara Breakers - uma das primeiras equipes de breaking.

No início do livro há uma apresentação do então Secretário de Educação, Cultura e Esportes, Luiz Roberto Alves, e uma reconstituição do projeto “Movimento de Rua" feita pelos coordenadores Carlos Bahdur Vieira, Ronaldo de Oliveira, Júlio Mendonça e Neuza Pereira Borges. Um trecho da apresentação de Luiz Roberto Alves expressa a preocupação do intelectual-político com o futuro daquelas construções simbólicas. Sua análise destaca a combinação do local e global, as possíveis apropriações pelos meios de comunicação de massa e da necessidade das ações coletivas para manutenção da força política dos grupos. Previsão confirmada pela história.

De fato, a poética rap pretende ser, como diz o refrão: "canto de guerra diz a verdade que acontece na Terra". A sua internacionalização não mata o fato local, a realidade vivida no cotidiano. O que se espera é que a poética rap seja alternativa de poder à força da geleia geral imposta pelo consumo e pela comunicação massiva. Às vezes, as boas intenções de ser alternativa mascaram o projeto de apropriação cultural, que faz das ações comunitárias um acidente de percurso e um ingrediente na pasteurização geral. Nesse caso, tudo vai depender da criatividade grupal e das alianças sociais que ele realizar, a fim de estar sempre respondendo às profundas necessidades da vida, mesmo que com sacrifício de comodidade ou fama (ALVES, 1992, p. 5).

${ }^{13}$ Entrevista concedida por Blackalquimista ao autor em 18 mar. 2007. 
Ainda no início da década de 1990, as gangues de Hip Hop começaram a se formar, era o princípio do que seriam as posses - grupos de rap, de breaking e grafiteiros unidos para ajudar uns aos outros. DJ Fish achou que o grupo do Blackalquimista parecia um importante grupo de rap americano, o Boogie Down Productions. Uniram os grupos DJ Beat, Conexão Hip Hop, Crazy Boys, Inovators Rap, Ice Boys e fundaram a gangue Boogie Down Rappers (BDR). O objetivo principal era juntar dinheiro para comprar equipamentos e fazer discos. Bordavam camisetas com a sigla da gangue e faziam coreografia para cantar nos eventos. Os integrantes do Crazy Boys resolveram sair e criaram o Movimento Rap Organizado (MRO), iniciando uma disputa entre as gangues. Depois ambos os grupos se extinguiram e retornaram ao ponto de origem: a pista de skate. Em São Bernardo do Campo restava apenas o baile do Choppapo que acontecia aos domingos, mas a direção do baile havia proibido a entrada de pessoas com "bombeta" - boné na gíria dos "manos" -, e não existia rapper sem "bombeta", conforme relato de Blackalquimista. Com esse incidente, perceberam que tinham que se organizar fora dos limites da Prefeitura, também por causa da mudança de administração, que passou a não querer mais trabalhar com o Hip Hop. Reuniram-se na pista de skate: Ketu, Nino Brown, Afro X e Dexter (que depois foram presos e fundaram o grupo 509E, uma referência ao número da cela em que cumpriam pena), Blackalquimista, entre outros, com o intuito de organizar uma posse. Ketu sugeriu para o grupo o nome Hausa, etnia africana composta pelos negros mulçumanos responsáveis pela primeira revolta organizada dos negros escravizados, a Revolta dos Malês, nome que receberam quando chegaram ao Brasil. Assim, em 1993, foi fundada a Posse Hausa, pioneira no $\mathrm{ABC}$ Paulista, criada com um recorte racial definido, devido às experiências e à formação política dos seus integrantes. Eles iniciaram o trabalho na sede do projeto Meninos e Meninas de Rua, na rua Jurubatuba, no centro de São Bernardo do Campo. Em 1995, Honerê passou a integrar a Posse e, em 1996, tornou-se coordenador geral.

O Hip Hop tem cor sim! E essa cor é NEGRA com certeza! E nasceu para tirar os negros dos conflitos constantes que muitas vezes terminavam em morte. Hoje esse conceito "pluralista" na verdade faz de nós meros carregadores de piano enquanto outros grupos étnicos (brancos, japoneses) aparecem no cenário via mídia ganhando dinheiro explorando nossa cultura sem responsabilidade social com o grupo racial que desenvolveu essa cultura: NÓS NEGROS! (POSSE HAUSA, 2014).

A Posse Hausa nasce e cresce com esse recorte étnico-racial, sendo corroborado com o apoio, a orientação e as redes do MNU que, através dos seus dirigentes e militantes, enxergavam 
no Hip Hop um caminho de fortalecimento e rejuvenescimento das formas de atuação, organização e expressão do Movimento Negro brasileiro. Honerê explica esse processo de aproximação com a Posse Hausa e o MNU:

Mas quando eu entrei no MNU, o MNU tinha uma intervenção em Diadema e em São Bernardo, então a gente tinha um contato com essas pessoas aí a gente já circulava, começava a participar das reuniões deles. Esse recorte étnico-racial veio desde o início, inclusive, muitas pessoas que estavam na quadra pro lançamento da Hausa não entraram na Hausa pelo recorte racial. Se fosse uma posse só de Hip Hop, teria um número muito maior de participantes, mas não teria a mesma pegada que tem até hoje. A Hausa você já identifica, através de suas ações, o seu diferencial político em relação a outras posses de Hip Hop; e esse diferencial político vem através dessa convivência e dessa experiência passada entre Hausa e MNU: muitos jovens do MNU aprenderam com a Hausa e muitos jovens do MNU ensinaram à Hausa critérios raciais importantes (HONORÊ apud BASTOS, 2008a, p. 238).

Depois que participei de um evento promovido pela Posse Hausa, o "Hip Hop É na Rua”, que acontece quinzenalmente em comunidades periféricas, com basquete de rua, Hip Hop e informação, consegui marcar uma entrevista com Honerê. Naquela ocasião, era véspera de um campeonato de basquete street na quadra da Escola Estadual Professor Walker da Costa Barbosa, no Parque São Bernardo, em São Bernardo do Campo, onde membros da entidade como o DJ Simão Malungo, do grupo Alquimistas, e Honerê faziam a discotecagem e passavam mensagens positivas para crianças, jovens e adolescentes da periferia.

A entrevista aconteceu na sede do Centro de Divulgação do Islam para América Latina (CDIAL), onde ele trabalhava como auxiliar de escritório. O CDIAL é uma fundação beneficente, cultural e social islâmica, independente, que atua na divulgação do conhecimento islâmico e em defesa das questões muçulmanas. Também trabalha na manutenção da imagem do Islã para os não muçulmanos, buscando um contraponto à imagem negativa propagada pelos meios de comunicação de massa. Em São Bernardo do Campo há uma grande comunidade de muçulmanos, e Honerê relata que aprende muito com a rede que eles têm, pois são muito unidos, articulados e dão apoio para as pessoas que vêm da mesma região ou são da mesma religião. Ele observa que essas pessoas não vieram para cá sequestradas e violentadas, como os africanos, senão estariam no mesmo patamar de organização. Honerê se converteu ao Islamismo em 1996 e, desde então, utiliza o nome Honerê Al-Amin Oadq: Honerê é a abreviação de Homem Negro que Resiste; Al-Amin é uma referência ao nome do profeta Mohamed, que é dado a ele antes 
da revelação do Islã ou do Alcorão - ele era considerado uma pessoa justa e verdadeira e todas as pessoas da mesma tribo o tinham como uma pessoa de confiança para resolver os principais problemas; Oadq é a abreviação de origem africana de descendência quilombola.

Honerê nasceu na cidade de Diadema, em 1977, morava no Jardim União e cresceu frequentando a região do Jardim Inamar, - onde estudava, por isso estava sempre com as pessoas da comunidade -, e também no Eldorado e na Sapobemba, onde tinha muitos amigos. Esses espaços foram os berços de nascimento do Movimento Hip Hop no município, e foi ali que Honerê teve os primeiros contatos com os elementos artísticos do Hip Hop e houve o despertar de uma consciência política acerca de sua identidade étnico-racial. O caminho para adquirir consciência da sua história, da sua identidade, do seu papel junto aos seus pares, jovens negros como ele, passou pela infância e adolescência na cidade de Diadema dos anos 1980, quando esta possuía os índices mais alarmantes de violência do país. E esse despertar da sua condição étnico-racial foi adquirido através de experiências conflituosas, como foi para outros jovens como ele, algumas vezes traumáticas, ao sentir e não saber como enfrentar o racismo. Os meios de comunicação de massa funcionaram como aqueles espelhos que distorcem e desfiguram nossa imagem, e suas representações balizaram a construção de sua subjetividade, posteriormente convertida em ações objetivas de enfrentamento simbólico, no qual o Hip Hop assumiu o papel central, na urdidura de sua identidade étnica.

Diadema, diferente do que ela é hoje, era uma das cidades mais violentas do país. Você tinha um grau de assassinatos, de extermínio muito grande. E tinha poucas frentes de combate a esse extermínio, então você já vivia numa tensão junto à polícia, enfim... A relação poder público e sociedade civil era das piores possíveis. E aí tinha o lado do racismo, em si, que era reproduzido pelos meios de comunicação; você vê crianças brancas, que não eram a maioria onde a gente vivia, mas existia, e elas reproduzindo aquele mesmo racismo que é colocado na TV, que insistentemente glorifica através de padrões de beleza, de boa aparência, a raça do indivíduo branco europeu e menospreza a maioria dessa população brasileira que tem outras características, outros valores, que não eram de forma alguma reproduzidos nesses meios de comunicação. E, quando eles vinham para esses meios, era de forma pejorativa, onde você sempre era o pior, o que fazia errado, o mais feio, o mais enrolado. No caso da mulher: a mulher sem vergonha. Isso foi um causador de problemas pra diversos jovens da minha época, então eu cresci com isso (HONORÊ apud BASTOS, 2008a, p. 171). 
Honerê explica que foi no Jardim Inamar, quando conheceu o rap, que começou sua militância política, ainda no final da década de 1980. O que motiva um jovem, uma criança ou um adolescente a se envolver com o Hip Hop é a vontade de se expressar, de se divertir, dentro de um ambiente onde os espaços e as ferramentas de lazer e ação cultural são escassos. "Eu entrei no rap com a perspectiva de diversão, de entretenimento, e aí a fisgada militante da época me arrastou pra essa linha. Aí até hoje eu permaneço nessa mesma linha, dentro do Hip Hop”, disse ele na entrevista. Os meninos e as meninas do Hip Hop, sobretudo estes da primeira e segunda geração, desempenhavam um verdadeiro trabalho de bricoleur, buscando organizar e harmonizar as peças disponíveis, compondo sentidos e construindo belezas a partir dos fragmentos, tanto materiais como simbólicos, que contornavam a realidade da periferia. Honerê começou dançando com um grupo de rap, depois houve a possibilidade de cantar e montar um grupo. Depois se interessou pela arte de DJ, começou a discotecar no grupo Zenzelê e a cantar no grupo Banzo Bantu. O grupo teve início por volta de 1991, quando conheceu duas pessoas que se tornaram muito importantes em sua vida, primeiramente o Ketu, depois o San, ambos filiados ao MNU e fundadores da Posse Hausa, em 1993. Por afinidade política, eles decidiram montar um grupo de rap que expressasse essa identificação, daí surgiu o Banzo Bantu. Como o grupo enaltece a temática racial em suas letras, ele explica que não há espaço no mercado, então costumam se apresentar em movimento de rua, dentro da linha política de recorte racial.

As experiências cotidianas balizavam a compreensão do Movimento Hip Hop, que foi se matizando em faces complementares, não conflitantes, mas, conforme as subjetividades eram moldadas, os agentes do Hip Hop buscavam orientação e formação política mais fundamentada, seja na questão racial, social ou cultural, passando a ocorrer maior elaboração, mas também maior conflito de ideias. Para Honerê, o sentido do Hip Hop ficava, cada vez mais, atrelado à história do negro e à formação de uma identidade étnico-racial, e as questões sociais, comunicacionais, culturais e estéticas passaram a ser mediadas por esse prisma.

A gente, graças a Deus, no momento de tudo dessa questão de valores, de consumo, que possa vir da minha vida, da minha juventude, foi um momento em que eu tava dentro do Movimento Hip Hop, que já me dava um tipo de instrução na época, que me exigia um tipo de conhecimento e formação, na época; a formação me levou dentro do Movimento Negro Unificado, que foi dentro dessa organização que me formou, que me fez entender a minha responsabilidade enquanto ser negro; porque nascer negro é uma condição, mas você ser negro é um ato político, e a gente, hoje, entende isso muito bem graças a essa organização.[...] As gangues de Hip Hop, as posses, tinham um 
papel importante pra essa formulação, a gente só foi entender isso depois (HONORÊ apud BASTOS, 2008a, p. 179).

\section{Considerações finais}

As subjetividades destes jovens agentes sociais do Hip Hop foram erigidas a partir de condições objetivas e concretas, historicamente e cientificamente observáveis, como a luta de classes, os processos materiais e simbólicos de exclusão e discriminação do povo negro, das classes populares; e estas mesmas subjetividades, reelaboradas através de processos e ações sociais e culturais, dialeticamente, engendram propostas objetivas de construção de outra ordem social, que, por sua vez, podem propiciar a urdidura de novas subjetividades e de novos sujeitos coletivos. A história de vida de Honerê e o amiúde aflorar de uma consciência política racial, o elã em propagar este despertar numa rede, cada vez mais ampla, confirmam o andamento desse complexo processo histórico, de matizes sociais, culturais, raciais e políticas. Como afirma Honerê na entrevista: "Quando veio o Hip Hop, ele deu a oportunidade de colocar essas angústias pra fora, de encontrar pessoas iguais a você, que conseguiam ter um condicionamento informativo que te mostrava outros caminhos: 'Olha, você tem história, você tem referências..."”. O Movimento Hip Hop foi o principal meio de apreensão e mediação dessa realidade, bem como de comunicação em rede dessas construções simbólicas, seja em discursos, música, dança ou arte plástica, prenhe de visão de mundo.

O Movimento Hip Hop tem o poder de aglutinar a juventude da periferia em torno dos seus elementos artísticos. Essa atração é exercida por fatores como a ampla possibilidade de se expressar, de socializar ideias e sentimentos com seus semelhantes, de se destacar artística, cultural e socialmente e se compreender como sujeito individual e coletivo. Dessa forma, o Hip Hop se torna ponto de partida e interface para a compreensão de diversos fenômenos e processos sociais que tocam o cotidiano da juventude da periferia. Em uma sociedade exploradora, opressora, elitista, machista e racista, com mínimas possibilidades de mobilidade social, o Hip Hop possibilita acreditar, imaginar e lutar por outra existência através de suas ações e práticas políticas, sociais e culturais cotidianas. 


\section{Referências bibliográficas}

ALVES, Luiz Roberto. O rap, contra o rapa das ruas. In: OLIVEIRA, Ronaldo de; BORGES, Neuza Pereira; VIEIRA, Carlos Badhur (Coord.) e MENDONÇA, Júlio (Org.). ABC RAP. São Bernardo do Campo: Secretaria de Educação, Cultura e Esportes - SECE, 1992.

ANDRADE, Elaine Nunes de. Movimento negro juvenil: um estudo de caso sobre jovens rappers de São Bernardo do Campo. 1996. 317 f. Dissertação (Mestrado em Educação) - Faculdade de Educação, Universidade de São Paulo, São Paulo, 1996.

BASTOS, Pablo Nabarrete. FACES DO ESPELHO: Processos de construção de sentidos sobre o Movimento Hip Hop do ABC Paulista. Revista Passagens - Programa de Pós-Graduação em Comunicação da Universidade Federal do Ceará, Fortaleza, v. 5, n. 1, p. 133-152, 2014.

Ecos de espelhos - movimento Hip Hop do ABC Paulista: sociabilidade, intervenções, identificações e mediações sociais, culturais, raciais, comunicacionais e políticas. 2008. 325 f. Dissertação (Mestrado em Interfaces Sociais da Comunicação) - Escola de Comunicações e Artes, Universidade de São Paulo, São Paulo, 2008a.

O jogo de espelhos. In: FUSER, Bruno (Org.). Comunicação para a Cidadania: caminhos e impasses. Rio de Janeiro: E-papers, 2008b, p. 285-305.

CUCHE, Denys. A noção de cultura nas ciências sociais. Bauru: EDUSC, 2002.

FELIX, João Batista de Jesus. Hip Hop: Cultura e política no contexto paulistano. 2006. 206 f. Doutorado (Antropologia Social) Faculdade de Filosofia, Letras e Ciências Humanas, Universidade de São Paulo, 2006.

Chic Show e Zimbabwe: a construção da identidade nos bailes black paulistanos. 2000. 202 f. Dissertação (Mestrado em Antropologia Social) - Faculdade de Filosofia, Letras e Ciências Humanas, Universidade de São Paulo, 2000.

GITHAY, Celso. O que é graffiti. São Paulo: Brasiliense, 1999.

HALL, Stuart. A identidade cultural na pós-modernidade. Rio de Janeiro: DP\&A, 1999.

IANNI, Octavio. Raças e classes sociais no Brasil. São Paulo: Brasiliense, 2004.

POSSE HAUSA. Posse Hausa: Hip-Hop com Responsabilidade Social!, c2014. Página inicial. Disponível em: http://possehausa.blogspot.com/. Acesso em: abr. 2008.

ROCHA, Janaina; DOMENICH, Mirella; CASSEANO, Patrícia. Hip Hop - A periferia grita. São Paulo: Fundação Perseu Abramo, 2001. 